Bull. Chem. Soc. Ethiop. 2018, 32(2), 371-386.

ISSN 1011-3924

(c) 2018 Chemical Society of Ethiopia and The Authors

Printed in Ethiopia

DOI: https://dx.doi.org/10.4314/bcse.v32i2.15

\title{
HYDROGEN EFFECT MODELING ON ZIEGLER-NATTA CATALYST AND FINAL PRODUCT PROPERTIES IN PROPYLENE POLYMERIZATION
}

\author{
Gholam Hossain Varshouee ${ }^{1}$, Amir Heydarinasab ${ }^{1 *}$, Ali Vaziri ${ }^{1}$ and Behrooz Roozbahani ${ }^{2}$ \\ ${ }^{1}$ Department of Chemical Engineering, Tehran Science and Research Branch, Islamic Azad \\ University, Tehran, Iran \\ ${ }^{2}$ Department of Chemical and Biomolecular Engineering, Research Associates of Rice \\ University, USA
}

(Received December 14, 2017; Revised March 22, 2018; Accepted May 2, 2018)

\begin{abstract}
Hydrogen, as chain transfer agent, effects on kinetic of propylene polymerization; consequently variation of hydrogen concentration leads to change final product properties and also activates site of used catalyst. This phenomenon is one of the most important process variables is to adjust the final product properties and optimize the operating conditions. This work has attempted to present a mathematical model that cable to calculate the most important indices of end used product, such as melt flow index, number and weight average molecular weight and poly dispersity index. The model can predict profile polymerization rates determining important kinetic parameters such as the activation energy, lumped deactivation reaction initial reaction rate and deactivation constant. The mathematical model was implemented in Matlab/Simulink environment for slurry polymerization in laboratory scale. The modeling approach is based on polymer moment balance method in the slurry semi-batch reactor. In addition, in this work have provided a model that calculating fraction activated sites catalyst via hydrogen concentration. The model was validated by experimental data from lab scale, reactor. The experimental and model outputs were compared; consequently, the errors were within acceptable range.
\end{abstract}

KEY WORDS: Mathematical modeling, Propylene polymerization, Kinetics study, Hydrogen response, population balance

\section{INTRODUCTION}

Polypropylene is one of the widest used polyolefin product and its application is strongly affected by the final product properties. It could be said that the most crucial indices of end used product of polypropylene are comprised of the melt flow index, number average molecular weight, weight average molecular weight, and polydispersity index. These indices depend heavily on independent operational variables such as temperature and hydrogen concentration, as well as the kinetics of polymerization. Hence, hydrogen as a chain transfer agent is one of the most vital affecting factors on the reaction kinetics and final product properties. On the other hand, the impact of hydrogen on catalyst activity in the course of olefin polymerization is less predictable and its effect depends on the type of catalyst and monomer. For instance, hydrogen generally reduces the polymerization rate of ethylene and increases the polymerization rate of propylene when high-activity $\mathrm{TiCl}_{4} / \mathrm{MgCl}_{2}$ catalysts are used [1]. As reported that hydrogen leads to extra activated sites and yield of the catalyst [1].

Despite sixty years of history of the use of Ziegler-Natta catalyst for manufacturing polypropylene, polymerization system performance it still remains as a black box [2]. However, it has been found that kinetics of polymerization with Ziegler-Natta catalysts is quite complicated [3]; particularly, when hydrogen exists in the polymerization reaction. So far, more research to understand the polymerization system has been carried out in a conventional manner based on trial and error or experimental approach; although this methodology isn't reliable and applicable because it's heavily dependent on test and laboratory conditions. Hence, a validated

*Corresponding author. E-mail: a.heidarinasab@srbiau.ac.ir

This work is licensed under the Creative Commons Attribution 4.0 International License 
model that could be able to predict the impact of hydrogen of polymerization rate, final product properties, vital kinetics parameters and most of all calculating activated site percentage and yield of the catalyst by changing the concentration of hydrogen is inevitable. Up to now despite disputing on the role of hydrogen upon the polymerization, to the best of our knowledge there is no validated mathematical model presented that could be able to predict mentioned gaps simultaneously. In this study, we tried to propose a validated model to cover the gap.

To date, more articles published on the field of polypropylene polymerization modeling have been concerned with heat and mass transfer inside the catalyst particles the slurry polymer particles [4-5] or on the basis of the mechanism of reaction and how the particle increase regarding multigrain [6-8]. Their models have been focused on mathematical calculations without validation with experimental data. The other researchers were only targeted on loop reactors [2, 9] and fluidized-bed reactors (FBRs) [10], namely bulk and gas phase polymerization that they are not applicable to slurry reactor. In the regard to rate profiles of propylene polymerization, the first article in the liquid phase (i.e. bulk polymerization, no slurry) was issued by Samson et al. [11] and some authors investigated the hydrogen effect on kinetics experimentally without paying attention to polymerization rate and final product properties $[12,13]$.

Al-haj Ali et al. proposed a generalized model for hydrogen response based on the dormant site theory in liquid propylene polymerization [14]. His research work was based on experimental data, and there was no validated mathematical model that might be capable of predicting polymerization rate profile and indices final product properties simultaneously. Zacca et al. modeled industrial scale loop reactor by using non-ideal continuous stirred tank model to explain the industrial process and compared their simulation results with commercial plant data. The research targets defined to predict the macroscopic of the process, dynamics of the plant, advanced control strategies, grade transitions, and average polymer. In the paper, despite offering formulas for some important final properties such as number average molecular weight $\left(\mathrm{M}_{\mathrm{n}}\right)$; weight averages molecular weight $\left(\mathrm{M}_{\mathrm{w}}\right)$ and polydispersity index (PDI); no mentioned about validating the model with them. Furthermore, no considered concerning the effect of hydrogen on the vital indices of final production and kinetics and catalyst activation [3].

In relation to investigating hydrogen effect during propylene polymerization, many experimental studies have been carried out, but the results of these studies have been ambiguous and even contradictory. Guastalla and Gianinni experimentally concluded that when hydrogen exists in the system, the initial rate and activity of catalyst increase about 2.5 times than when not hydrogen in propylene polymerization reactor [15]. Spitz et al. described that low hydrogen concentrations in the reactor lead to causes of the enhancement of the rate profile, higher hydrogen levels increased lowered activity and increased deactivation [16]. Rishina et al. reported that in their study, there was a similar activation effect for hydrogen and they pointed out that such an effect is reversible and temporarily [17]. Some scholars confirmed a similar hydrogen activation effect for different catalyst types and polymerization media [10, 18]. Contrary to these findings, Soga and Siona obtained that propylene polymerization rate decreases with increasing hydrogen partial pressure. The authors justified their findings happened due to the slow addition of the monomer to the catalyst-hydrogen bond formed in the step of chain transfer to hydrogen [19]. Regardless of previous reports, Kahrman et al. achieved different conclusions and reported that hydrogen has not only an effect on the polymerization rate for low hydrogen concentrations but also the rate of polymerization decreases at high hydrogen concentration; the authors explained this phenomenon because of adsorbing hydrogen to activated sites of catalyst, amount of activated sites for polymerization are decreased, then the polymerization rate is reduced [20].

Nevertheless, up to now, these disputings have been continued. In 2013, Luo et al. modeled loop propylene polymerization reactors in bulk media. The model targeted on commercial reactor variables without paying attention to kinetics study and final product properties [21]. 
Next year, another paper published on modeling of multi-scale PP properties, but in FBR reactor [22]. Recently, in 2016, Song et al. drew their attention to a simulation of liquid polypropylene polymerization reactors based on Sheripol technology as well as preceding work. Although they paid attention to some final product properties such as average molecular weight and polydispersity, their simulation was not suitable for kinetics study and predicting final product properties [23].

On the whole, in regarding conflicting results reported, particularly while hydrogen exists in the reactor system; the effect of hydrogen on the reactor is still vague and unclear. Consequently, a validated model of profile polymerization rate that could be predicted correctly the system is inevitable. Despite the importance of the matter, a few investigators have been pied attention to this subject, however so far, no a comprehensive validated model to reply the existing gap has been presented. The aim of this work is to present a validated model to predicting profile polymerization rate, the effect of hydrogen concentration on profile rate, calculating the model of the fraction activated sites catalyst via hydrogen concentration and identifying vital kinetic parameters such as $\left(\mathrm{E}_{\mathrm{a}}, \mathrm{E}_{\mathrm{p}}, \mathrm{Rp}_{0}, \mathrm{~K}_{\mathrm{d}}\right)$. In addition, the model is capable to calculate the most important final product index, such as melt flow index (MFI), number average molecular weight $\left(\mathrm{M}_{\mathrm{n}}\right)$, weight average molecular weight $\left(\mathrm{M}_{\mathrm{w}}\right)$ and poly dispersity index (PDI). In addition, another purpose of this paper is to reveal the impact of hydrogen content on the fraction of activated catalyst sites during polymerization. The model was carried out in a Matlab/Simulink environment and afterward, the model was validated with experimental data in slurry polymerization and investigated hydrogen response on the kinetic reaction. The global errors between the model outputs and experimental data are an acceptable margin of error.

\section{EXPERIMENTAL}

\section{Materials}

The 4th generation of spherical $\mathrm{MgCl}_{2}$ supported Ziegler-Natta catalyst containing $3.6 \mathrm{wt} \% \mathrm{Ti}$ and diisobutyl phthalate (DIBP) as internal donor supplied by Sudchemie, Germany. Triethylaluminium (TEA of $98 \%$ purity) from Merck, Germany, diluted in n-heptane was used as a cocatalyst and the so-called external donor (cyclohexyl methyl dimethoxy silane) were purchased from Merck and was used without further purification. Polymer-grade propylene was provided from Shazand Petrochemical, Iran and was used as received. Hydrogen and nitrogen used were of $>99.999 \%$ purity. Nitrogen was further purified by passing over beds of absorbents.

\section{Polymer synthesis}

In this study, slurry homopolymerization was carried out in heptane media. Polymerization reactor was a one-liter stainless steel vessel manufactured by Buchi Co.; polymerization set-up was designed in order to conduct slurry polymerization in one vessel. A high-pressure $\mathrm{N}_{2}$ line was used to transfer liquid monomer and catalytic system into the reactor. The catalyst system was injected into the reactor through a stainless steel cylinder under $\mathrm{N}_{2}$ atmosphere. All gases were first purified online by passing through three purification trains (containing molecular sieves) in series. The individual gases were then filtered and flow of each reactant was measured and controlled with a mass flow controller manufactured by Brooks.

Experimental Rp-t curves come for setup monitor, then the molecular weight of products are measured by gel permeation chromatography (GPC), employing an Agilent PL-220 model with TSK columns at $155^{\circ} \mathrm{C}$ using 1,2,4-trichlorobenzene as a solvent. The GPC was calibrated with the narrow molecular weight distribution polystyrene standard as a reference. MFI of samples is evaluated according to ASTM 1238 at a temperature of $230^{\circ} \mathrm{C}$ and load of $2.16 \mathrm{~kg}$. 


\section{Polymerization procedure}

A typical polymerization procedure was consisting of reactor preparation, polymerization, and discharge. Details are as follows: Firstly, the reactor was flushed with nitrogen gas during 1 hour at $90{ }^{\circ} \mathrm{C}$ and was reduced reactor temperature until $20^{\circ} \mathrm{C}$, then purged with propylene gas in $15 \mathrm{~min}$. Afterward, $500 \mathrm{~mL}$ heptane as a solvent was introduced to the reactor; next, all the inputs and outputs of the reactor were closed and were stirred at $200 \mathrm{rpm}$ in $5 \mathrm{~min}$ for solvent degassing under a vacuum pump. Subsequently, hydrogen was entered to the reactor (based on recipe condition), then propylene was introduced to reactor according to controller program, then the reactor was heated up until reach to equilibrium thermodynamic conditions $(\mathrm{T}=70$ ${ }^{\circ} \mathrm{C}, \mathrm{P}=7.5$ bar), finally the reactor was ready to injecting catalyst for starting polymerization. Injecting catalyst to the reactor was carried out under pressure via an injection system during polymerization time (two hours) at the constant temperature and pressure, that is to say, the reactor was executed under isothermal and isobar reactor condition. Data were collected every five seconds.

It is worth mentioning that catalyst preparation should be done according to the recipe in a glove box under a nitrogen atmosphere $20 \mathrm{~min}$ before injection to the reactor. After each experiment, the resulting polymer was dried under an ambient condition under Laboratory hood for 24 hours.

\section{Modeling}

\section{Assumptions}

The following modeling assumptions are considered: (1) It was supposed that propylene polymerization was carried out in the amorphous phase and amorphous phase concentrations during the polypropylene polymerization are at the thermodynamic equilibrium condition that obeys from Sanchez and Lacombe Equation(SLE) [24] for calculating the amount of $\mathrm{X}=\mathrm{C}_{\mathrm{H}}$ / $\mathrm{C}_{\mathrm{m}}$, the hydrogen molar ratio. (2) It was assumed that $\gamma_{1}=\gamma_{2}=\cdots \cdot=\gamma_{\mathrm{NC}}$. Where $\gamma$ is equilibrium constant and $\mathrm{NC}$ is a number of solvent in slurry phase components [3]. (3) The reaction temperature, pressure, and monomer concentration were kept constant during the polymerization process. (4) The resistance of both mass and heat transfer and the diffusion effect of the reactants were ignored. (5) It was assumed that the propagation constant is independent of the length of the growing polymer chain. (6) Using "dormant sites theory" for activating catalyst by hydrogen concentration [14].

\section{Formulation}

As olefin polymerization kinetics with Ziegler-Natta catalysts might be fairly complicated [3]. To date, several reaction steps have been proposed in the literature [3, 9]. However, the most comprehensive steps were proposed by Zacca [3]. The ODE mass balance equations in the model are as follows:

$$
\frac{d C_{j, R}}{d t}=\left[\frac{Q_{f} C_{j, f}}{V_{R}}\right]_{\text {feed (input) }}-\left[\frac{(\eta / \zeta) Q_{0} C_{j, R}}{V_{R}}\right]_{\text {output }}+R_{j}
$$

where

$$
\begin{array}{cc}
C_{j, R}=\frac{\text { Mole of } j}{\text { Total Volume }} & \text { for } \mathrm{j}=1,2, \ldots, \mathrm{NC} \\
\eta_{j}=\frac{C_{j, a}}{C_{j, l}} & \text { for } \mathrm{j}=1,2, \ldots, \mathrm{NC}
\end{array}
$$


$\zeta_{j}=\frac{C_{j, o}}{C_{j, R}}=\frac{\rho_{0}}{\rho_{R}} \cdot D_{f} \quad$ where : $\quad(\eta / \zeta)=\left\{\begin{array}{l}\eta \text { for liquid phase components } \\ \zeta \text { for solid phase components }\end{array}\right.$

$Q_{f}, \mathrm{Q}_{0}$, and $\mathrm{Q}_{\mathrm{R}}$ are feed volumetric flow rate, reactor-output volumetric flow rate and volumetric recirculation flow rate in respectively. In addition to Eq. (1), $V_{R}$ and $R_{j}$ are defined as reactor volume and $\mathrm{j}$ component reaction rate.

Since the model is a semi-batch process and assumed constant monomer concentration during the polymerization, the input and output terms are eliminated $\left(\mathrm{Q}_{\mathrm{f}}\right.$ and $\left.\mathrm{Q}_{0}\right)$ then the terms of $\eta$ and $\zeta$ are meaningless for our study. Table 1 shows possible reactions with their rate equations in the polymerization reactor. The concentration variations with time used in modeling are as follows:

$$
C_{j}=C_{H}, C_{A}, C_{E}, C_{M i}, C_{B}, C_{S}, C_{c a t}, P_{\mathbf{0}}^{k}, \mu_{\mathbf{0}}^{k}, \mu_{\mathbf{1}}^{k}, \lambda_{\mathbf{0}}^{k}, \lambda_{\mathbf{1}}^{k}, \lambda_{\mathbf{2}}^{k}
$$

where $\mathrm{k}$ is site number of the catalyst. In this study, it is supposed that the catalyst has monosite, and then $\mathrm{k}$ is equal to one. Here, $\mathrm{C}_{\mathrm{H}}, \mathrm{C}_{\mathrm{A}}, \mathrm{C}_{\mathrm{E}}, \mathrm{C}_{\mathrm{Mi}}, \mathrm{C}_{\mathrm{B}}, \mathrm{C}_{\mathrm{S}}, \mathrm{C}_{\text {cat }}$, and $\mathrm{P}_{0}$ are the concentration of hydrogen, co-catalyst (aluminum alkyl), electron donor, monomer, poison, site transfer, catalyst and potential site in the polymerization in respectively. Table 2 listed the component rate equations and moment equations have been used in the model. The final product properties of polypropylene can be estimated by the moment equations. The basic polymer properties, called as end-use properties, are four items; Number average molecular weight $\left(M_{n}\right)$, weight average molecular weight $\left(\mathrm{M}_{\mathrm{w}}\right)$, melt flow index (MFI) and polydispersity index (PDI). The relationship between the moment and these indices are defined by the following equations:

$$
\begin{aligned}
& \overline{M_{n}}=\sum_{K=1}^{N s} \sum_{i=1}^{N m} \frac{\lambda_{\delta_{i}}^{k}}{\lambda_{0}^{k}} \overline{M_{i}} \\
& \overline{M_{w}}=\lambda_{2} \cdot \sum_{k=1}^{N s} \lambda_{0}^{k} \overline{M_{n}}
\end{aligned}
$$

Then : $\quad D P I=\frac{\overline{M_{w}}}{\overline{M_{n}}}$

As melt flow index is a function of molecular weight through, the below power-law-type equation is suggested.

$$
M F I=a \cdot\left(\overline{M_{w}}\right)^{b}
$$

$\mathrm{a}$ and $\mathrm{b}$ parameters are calculated by fitting proprietary experimental data. It will be discussed later in results and discussion.

\section{Determination of the kinetic parameters}

A typical polymerization rate profile is comprised of two following area; (I) initial polymerization start-up zone and (II) the quasi-steady-state zone [14]. Each zone has a significant meaning in the kinetic analysis; detailed discussions of these issues have a considerable debate and are not repeated here for the sake of brevity.

Pater et al. [12] and some other researchers [13, 14] have showed the rate of polymerization at isothermal conditions can be described as a first-order process in monomer concentration and the deactivation of the catalyst as a first-order process in the number of active sites, the following equations are used: 


$$
\begin{aligned}
& R_{p}=K_{p} C_{m} C=R_{p 0} \bullet \exp \left(-k_{d} \mathrm{o} t\right)=R_{p 0} \bullet \exp \left(-\frac{E_{a}}{R . T}\right) \\
& \frac{d C^{*}}{d t}=-K_{d} C, \text { where } \mathrm{K} k_{d}=k_{d \mathbf{0}} \cdot \exp \left(\frac{-E_{a, d}}{R T}\right)
\end{aligned}
$$

Here, $\mathrm{Rp}_{0}$ is the initial reaction rate, $\mathrm{k}_{\mathrm{d}}$ the deactivation constant, $\mathrm{E}_{\mathrm{a}, \mathrm{d}}$ the activation energy for the lumped deactivation reaction, $\mathrm{C}$ activated site of the catalyst during polymerization, $\mathrm{t}$ shows time, and $\mathrm{T}$ indicates the temperature. So it could be calculation with profile rate curve of polymerization $(\mathrm{t}=0)$.

Obviously, for finding $\mathrm{Rp}$ at the isothermal condition, two parameters namely $\mathrm{Rp}_{0}$ and $\mathrm{K}_{\mathrm{d}}$ should be obtained. The $\mathrm{Rp}_{0}$ and $\mathrm{K}_{\mathrm{d}}$ are determined graphically by plotting the natural logarithm of the reaction rate versus polymerization time, a linear fit can be made where the slope of the fit line is $\mathrm{K}_{\mathrm{d}}$, and the intercept is $\mathrm{Rp}_{0}$. Due to the rate of polymerization has a dependency on temperature, with having $\mathrm{Rp}_{0}$ at different temperatures by using Arrhenius Eq. (6), the activation energy of any type of catalyst is easily predictable.

\begin{tabular}{|c|c|c|c|}
\hline \multirow{4}{*}{$\begin{array}{l}\text { Reaction step } \\
\text { Site activation }\end{array}$} & Component & Reaction & Rate equation \\
\hline & Hydrogen & $C_{p}+H_{2} \rightarrow P_{0}^{K}$ & $R_{a H}^{K}=k_{a H}^{k} C_{p} C_{H, a}^{O_{a H}^{K}}$ \\
\hline & Al-alkyl & $C_{p}+A \rightarrow P_{0}^{K}+B$ & $R_{a A}^{K}=k_{a A}^{k} C_{p} C_{A, a}^{O_{a A}^{K}}$ \\
\hline & Monomer $i$ & $C_{p}+M_{i} \rightarrow P_{0}^{K}+M_{i}$ & $R_{a M i}^{K}=k_{a M i}^{k} C_{p} C_{M i}^{O_{a M i}^{K}}$ \\
\hline Chain initiation & Monomer $i$ & $P_{0}^{k}+M_{i} \rightarrow P_{\delta_{i}, i}^{K}$ & $R_{P 0 i}^{K}=k_{P 0 i}^{k} P_{0}^{K} C_{M_{i}, a}$ \\
\hline Chain propagation & Monomer $j$ & $P_{n, i}^{K}+M_{j} \stackrel{K p}{\rightarrow} P_{n+\delta_{j}, j}^{K}$ & $R_{P j i}^{K}=k_{P j i}^{k} P_{n, j}^{K} C_{M_{j}, a}$ \\
\hline \multirow[t]{2}{*}{ Chain transfer } & Hydrogen & $P_{n, i}^{K}+H_{2} \stackrel{K h}{\rightarrow} P_{0}^{K}+D_{n}^{k}$ & $R_{c H i}^{K, n}=k_{c H i}^{k} P_{n, i}^{K} C_{H, a}^{O_{c H i}^{K}}$ \\
\hline & Monomer $j$ & $P_{n, i}^{K}+M_{j} \stackrel{K m}{\rightarrow} P_{\delta_{j}, j}^{K}+D_{n}^{k}$ & $R_{c M_{j i}}^{K, n}=k_{c M_{j i}}^{k} P_{n, i}^{K} C_{j, a}^{K}$ \\
\hline \multirow[t]{5}{*}{ Site deactivation } & Hydrogen & $P_{n, i}^{K}+H_{2} \rightarrow C_{d}+D_{n}^{k}$ & $R_{a H i}^{K, n}=k_{d H}^{k} P_{n, i}^{K} C_{H, a}^{O_{d H}^{K}}$ \\
\hline & & $P_{0}^{K}+H_{2} \rightarrow C_{d}$ & $R_{d H 0}^{K}=k_{d H}^{k} P_{0}^{K} C_{H, a}^{O_{d H}^{K}}$ \\
\hline & Al-alkyl & $P_{n, i}^{K}+A \rightarrow C_{d}+D_{n}^{k}$ & $R_{d A i}^{K, n}=k_{d A}^{k} P_{n, i}^{K} C_{A, a}^{O_{d A}^{K}}$ \\
\hline & Spontaneous & $P_{n, i}^{K} \rightarrow C_{d}+D_{n}^{k}$ & $R_{d S p i}^{K, n}=k_{d S p}^{k} P_{n, i}^{K}$ \\
\hline & & $P_{0}^{K} \rightarrow C_{d}$ & $R_{d S p 0}^{K}=k_{d S p}^{k} P_{0}^{K}$ \\
\hline \multicolumn{4}{|c|}{ Using dormant sites theory [14] } \\
\hline \multicolumn{2}{|c|}{ Dormant site formation } & $C_{j}+M \stackrel{K_{s}}{\longrightarrow} S$ & \\
\hline \multicolumn{2}{|c|}{ Dormant sites reactivation by $\mathrm{H}_{2}$} & $S_{j}+H_{2} \stackrel{K_{r e h}}{\longrightarrow}$ & \\
\hline \multicolumn{2}{|c|}{ Reactivation of dormant sites by monomer } & $S_{j}+M \stackrel{K_{P}}{\longrightarrow} S_{j+}$ & \\
\hline \multicolumn{2}{|l|}{ Deactivation } & $C_{j} \stackrel{K_{d}}{\longrightarrow} D_{j}$ & \\
\hline
\end{tabular}

Table 1. Possible reactions with their rate equations in the polymerization reactor. 
Table 2. The component rate and moment equations used in the model [3].

\begin{tabular}{|c|c|}
\hline Hydrogen & $R_{H}=-\sum_{K=1}^{N s}\left[R_{a H}^{k}+R_{r H}^{k}+R_{d H 0}^{k}+\sum_{i=1}^{N m} \sum_{n=\delta_{i}}^{\infty}\left(R_{c H i}^{k, n}+R_{d H i}^{k, n}\right)\right]$ \\
\hline Cocatalyst & $R_{A}=-\sum_{K=1}^{N s}\left[R_{a A}^{k}+R_{d A 0}^{k}+\sum_{i=1}^{N m} \sum_{n=\delta_{i}}^{\infty} R_{d A i}^{k, n}\right]-R_{e A}$ \\
\hline Electron donor & $R_{E}=-\sum_{K=1}^{N s}\left[R_{d E 0}^{k}+\sum_{\substack{l=1 \\
l \neq K}}^{N s} R_{t E 0}^{k l}+\sum_{i=1}^{N m} \sum_{n=\delta i}^{\infty}\left(\sum_{\substack{l=1 \\
l \neq K}}^{N s}\left(R_{t E i}^{l k, n}+R_{d E i}^{k, n}\right)\right]-R_{e E}\right.$ \\
\hline Poison & $R_{X}=-\sum_{K=1}^{N s}\left[R_{d X 0}^{k}+\sum_{i=1}^{N m} \sum_{n=\delta_{i}}^{\infty} R_{d X i}^{k, n}\right]-R_{e E}-R_{e A}$ \\
\hline Potential sites & $R_{C p}=-\sum_{K=1}^{N s}\left(R_{a H}^{k}+R_{a A}^{k}+R_{a S p}^{k}+\sum_{i=1}^{N m} R_{a M_{i}}^{k}\right)$ \\
\hline Vacant sites & 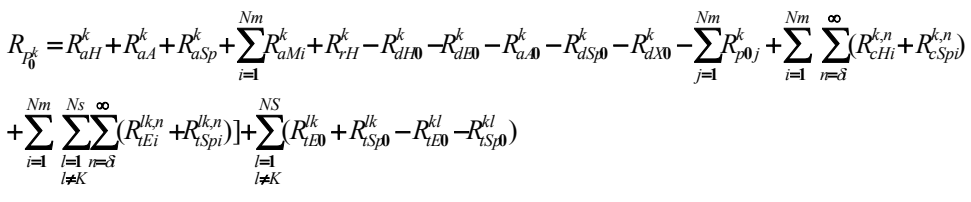 \\
\hline Dead sites & $\left.R_{C d}=\sum_{K=1}^{N s}\left(R_{d H 0}^{k}+R_{d E D}^{k}+R_{a A 0}^{k}+R_{d X 0}^{k}+R_{a S p \mid}^{k}-R_{r H}^{k}\right)+\sum_{i=1}^{N m} \sum_{n=\alpha}^{\infty}\left(R_{d H i}^{k, n}+R_{d E i}^{k, n}+R_{d A i}^{k, n}+R_{d X i}^{k, n}+R_{d S p i}^{k, n}\right)\right]$ \\
\hline Monomer & $R_{M i}=-\sum_{K=1}^{N s}\left[R_{P 0 i}^{k}+\sum_{j=1}^{N m} \sum_{n=\delta i}^{\infty}\left(R_{P i j}^{k, n}+R_{c M i, j}^{k, n}\right)\right]$ \\
\hline \multicolumn{2}{|l|}{ Moments equations } \\
\hline Live polymer & $R_{P_{n, i}^{k}}=\delta\left(n-\delta_{i}\right)\left[R_{P 0 i}^{k}+\sum_{j=1}^{N m} \sum_{m=\delta}^{\infty} R_{c M i j}^{k, m}\right]+\sum_{j=1}^{N m} k_{p i j}^{k} C_{M i, a} P_{n-\delta_{i}, j}^{k}-\sum_{j=1}^{N m} k_{p i j}^{k} C_{M j, a} P_{n, i}^{k}-\alpha_{i}^{k} P_{n, i}^{k}$ \\
\hline Dead polymer & 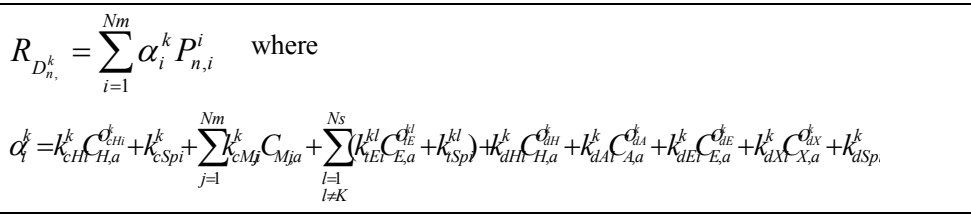 \\
\hline Live moment & $\mu_{\delta_{i, i}}^{k}=\sum_{n=1}^{\infty} n^{\delta_{i}} P_{n, i}^{k}$ \\
\hline Bulk moment & $\lambda_{\delta_{i}}^{k}=\sum_{n=\delta_{i}}^{\infty}\left(\sum_{i=1}^{N m} P_{n, i}^{k}+D_{n}^{k}\right)$ \\
\hline $\begin{array}{l}\text { Zero-order } \\
\text { live polymer moments }\end{array}$ & $R_{\mu_{0, i}^{K}}=R_{P 0 i}^{k}+\sum_{j=1}^{N m} k_{c M_{i}, j}^{k} C_{M i, a} \mu_{0, J}^{k}-\alpha_{i}^{k} \mu_{0, J}^{k}+\sum_{j=1}^{N m}\left[k_{p i j}^{k} C_{M i, a} \mu_{0, J}^{k}-k_{p j i}^{k} C_{M j, a} \mu_{0, i}^{k}\right]$ \\
\hline $\begin{array}{l}\text { First-order } \\
\text { live polymer moments }\end{array}$ & $R_{\mu_{\sigma i}^{k}}=\sum_{i=1}^{N m} \delta(i-l)\left[R_{P 0 i}^{k}+\sum_{j=1}^{N m} k_{c M_{i}, j}^{k} C_{M i a} \mu_{0, J}^{k}\right]-\sum_{i=1}^{N m} \alpha_{i}^{k} \mu_{\delta_{l}, i}^{k}+\sum_{i=1}^{N m} \sum_{j=1}^{N m} k_{p i j}^{k} C_{M i a} \delta(i-1) \mu_{0, J}^{k}$ \\
\hline $\begin{array}{l}\text { Zero-order } \\
\text { bulk polymer moments }\end{array}$ & $R_{\lambda_{0}^{K}}=\sum_{i=1}^{N m}\left[R_{P 0 i}^{k}+\sum_{j=1}^{N m} k_{c M_{i}, j}^{k} C_{M i, a} \mu_{0, J}^{k}\right]$ \\
\hline
\end{tabular}




\begin{tabular}{|l|l|}
\hline $\begin{array}{l}\text { First-order } \\
\text { bulk polymer moments }\end{array}$ & $R_{\lambda_{\delta l}^{k}}=\sum_{i=1}^{N m} \delta(i-l)\left[R_{P 0 i}^{k}+\sum_{j=1}^{N m} k_{c M_{i}, j}^{k} C_{M i, a} \mu_{0, J}^{k}\right]+\sum_{i=1}^{N m} \sum_{j=1}^{N m} \delta(i-1) k_{p i j}^{k} C_{M i, a} \mu_{0, J}^{k}$ \\
\hline $\begin{array}{l}\text { Second-order } \\
\text { bulk polymer moments }\end{array}$ & $R_{\lambda_{2}}=\sum_{K=1}^{N s} \sum_{j=1}^{N m}\left[R_{P O i}^{k}+\sum_{i=1}^{N m} k_{c M i j}^{k} C_{M j, a} \mu_{0, i}^{k}\right]+\sum_{k=1}^{N s} \sum_{i=1}^{N m} \sum_{j=1}^{N m} k_{p j i}^{k} C_{M j, a}\left(\mu_{0, i}^{k}+2 \mu_{1, i}^{k}\right)$ \\
\hline
\end{tabular}

Two very important notes should be considered about activation energy of Ziegler-Natta catalyst. First, it is independent of the hydrogen concentration [14]. Secondly, this is an intrinsic property of any catalyst and thus can be expected to differ from one type to another. The yield of the polymerization can be calculated by integrating the rate.

$$
Y_{\text {calc }}=\int_{0}^{t} R_{P} \cdot d t
$$

Amount of $Y_{\text {calc }}$ is exactly equal to the area under the profile curve. If this value is multiplied by the amount by weight of the catalyst, the produced polymer will be obtained in each batch. In experimental, the yield is measured by weighing the dry product from batch polymerization (as summarized in Table 1 for this study). But in fact, much more monomers are entered to the reactor, as called consumed monomer, that a part of them are reacted and the other part remains as an unconverted monomer in liquid and gas phases. The model is capable calculated yield and consumed monomer, directly.

\section{Hydrogen effect and dormant sites theory to determining $k_{p}$}

Propagation reaction is the most important reaction in the polymerization. Accordingly, determining the value of constant $\left(\mathrm{K}_{\mathrm{P}}\right)$ and activation energy $\left(\mathrm{E}_{\mathrm{p}}\right)$ are inevitable for modeling. We have used from the latest theory in regarding the effect of hydrogen on the catalyst sites. The theory is well-known to dormant sites theory. According to the theory, Since a propylene molecule is asymmetric with respect to the double bond, it has been suggested that monomers may insert at the catalyst site in four distinct arrangements (head to tail, tail to tail, tail to head and head to head). Growing chain has two positions of dealing with other monomers (position 12 and position 2-1). If growing chain reacts with position 2-1 of propylene, the dormant site will be created. Dormant sites are the drawback of propylene polymerization. Busico et al., have measured the distributions of end groups in polypropylene in the presence of hydrogen and have suggested that if the propylene molecule inserts in the 2-1 mode, the rate of propagation is reduced due to steric hindrance by the $\mathrm{Ti}$ atom [25]. These results are supported by the end group analysis done by Chadwick et al. [26].

According to the dormant sites theory, increasing the hydrogen concentration decreases the concentration of the dormant sites. A series of general formulas in accordance with the dormant sites theory for modeling have been proposed by Weickert et al., but the basis of their work was experimental and not attention to final product properties [14]. They are applied a "quasi-singlesite" model to explain the average behavior of the active sites. In addition, it is assumed that all active sites have the same average rate constants. The chain transfer with co-catalysts is neglected and a quasi-steady state is assumed for dormant sites.

In reality, the active sites of the catalyst are more or less covered by the polymer produced. The actual catalyst site concentration is between the maximum concentration of active sites $\mathrm{C}_{\max }$, and the concentration of dormant sites $\mathrm{C}_{\mathrm{s}}$. Therefore $\mathrm{C}$ from Eq. (6) can be written as the following:

$\mathrm{C}=\mathrm{C}_{\max }-\mathrm{C}_{\mathrm{S}}$

The concentration of the dormant sites can be calculated assuming the quasi-steady-state: 
$R_{S}=\mathbf{0}=K_{s} \cdot C \cdot C_{m}-K_{r e h} \cdot C_{s} \cdot C_{H \mathbf{2}}-K_{r e m} \cdot C_{s} \cdot C_{m} \rightarrow \therefore \quad C_{s}=\frac{K_{s} \cdot C}{K_{r e h} \cdot X+K_{r e m}}$

with $\mathrm{K}_{\mathrm{s}}, \mathrm{K}_{\mathrm{reh}}$ and $\mathrm{K}_{\mathrm{rem}}$ are rate constants for dormant sites formation, dormant sites reactivation by hydrogen and monomer reactions respectively. Where $\mathrm{X}$ is the hydrogen molar ratio $\mathrm{X}=$ $\mathrm{C}_{\mathrm{H}} / \mathrm{C}_{\mathrm{m}}$. Combining equations (9) and (10) leads to:

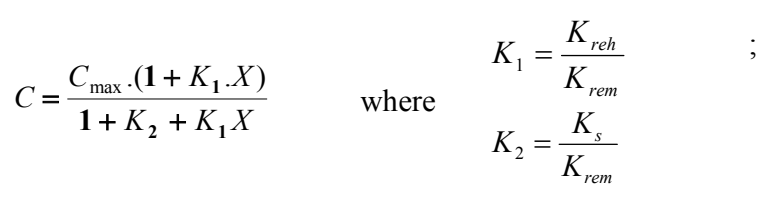

By inserting Eq. (11) in Eq. (6), we have the following equation.

$R_{p}=\frac{K_{p} \cdot C_{m} \cdot C_{\max } \cdot\left(K_{1} \cdot X+1\right)}{1+K_{1} \cdot X+K_{2}}$

$$
R_{p}=K_{p} \cdot C_{\max } \cdot C_{m} \cdot f_{H_{2}}
$$

Where:

$$
f_{H_{2}}=\frac{1+K_{1} \cdot X}{1+K_{2}+K_{1} \cdot X}
$$

$\mathrm{f}_{\mathrm{H} 2}$ represents the fraction of active sites in the system. In the absence of hydrogen $\mathrm{X}=0, \mathrm{f}_{\mathrm{H} 2}$ has the minimum amount. It means active sites of catalyst are at a minimum level in the polymerization system. Consequently, if $\mathrm{f}_{\mathrm{H} 2 \text {, max }}=1$, namely $100 \%$ of catalyst sites are active in reaction.

\section{Modeling algorithm}

In this study, we have outlined the algorithm for programming the mathematical model in a Matlab/Simulink environment, as shown in Figure 1(a). It is composed of two part; mainprogram (as named "Runsim") and subroutine (function file). For obtaining kinetic constants in the model, we propose a new method as iterative method algorithm by using consistency property of ODE's equation in Figure 1(B). The advantage of the method is more easy and trustable rather than the conventional manners; i.e. using directly from open literature [9] or estimating by trial and error [3]. For using the iterative method algorithm; only the initial guess of kinetic constants should be estimated by referring to open literature, afterward, the kinetic constants are adjusted for used the catalyst by the algorithm.

In this study, from literature $[3,9]$, the initial guess of kinetic constants was estimated and applied to the model, next the constants were exactly adjusted and determined in accordance with used the commercial catalyst in the set-up (experimental data) by the proposed algorithm in Figure 1(B). Investigating Figure 1(A) and (B) implies that the fairly accurate kinetic constants have been applied in the model.

\section{RESULTS AND DISCUSSION}

Comparison of the model output and experimental results in different condition are summarized in Table 3. The model has been validated by experimental data (as shown in Figure 2; in the absence of hydrogen concentration with different temperature and Figure 3 at the constant reactor temperature $\left(70{ }^{\circ} \mathrm{C}\right)$ with different hydrogen concentration). As it can be seen the experimental results and model outputs had in an acceptable margin of error. The margin of errors might be justified for the following reasons: (i) the global error that is the summation of 
truncation, method and round off error, (ii) personal and measurement equipment errors, (iii) selection of equation of state and (iv) errors resulting from assumptions.

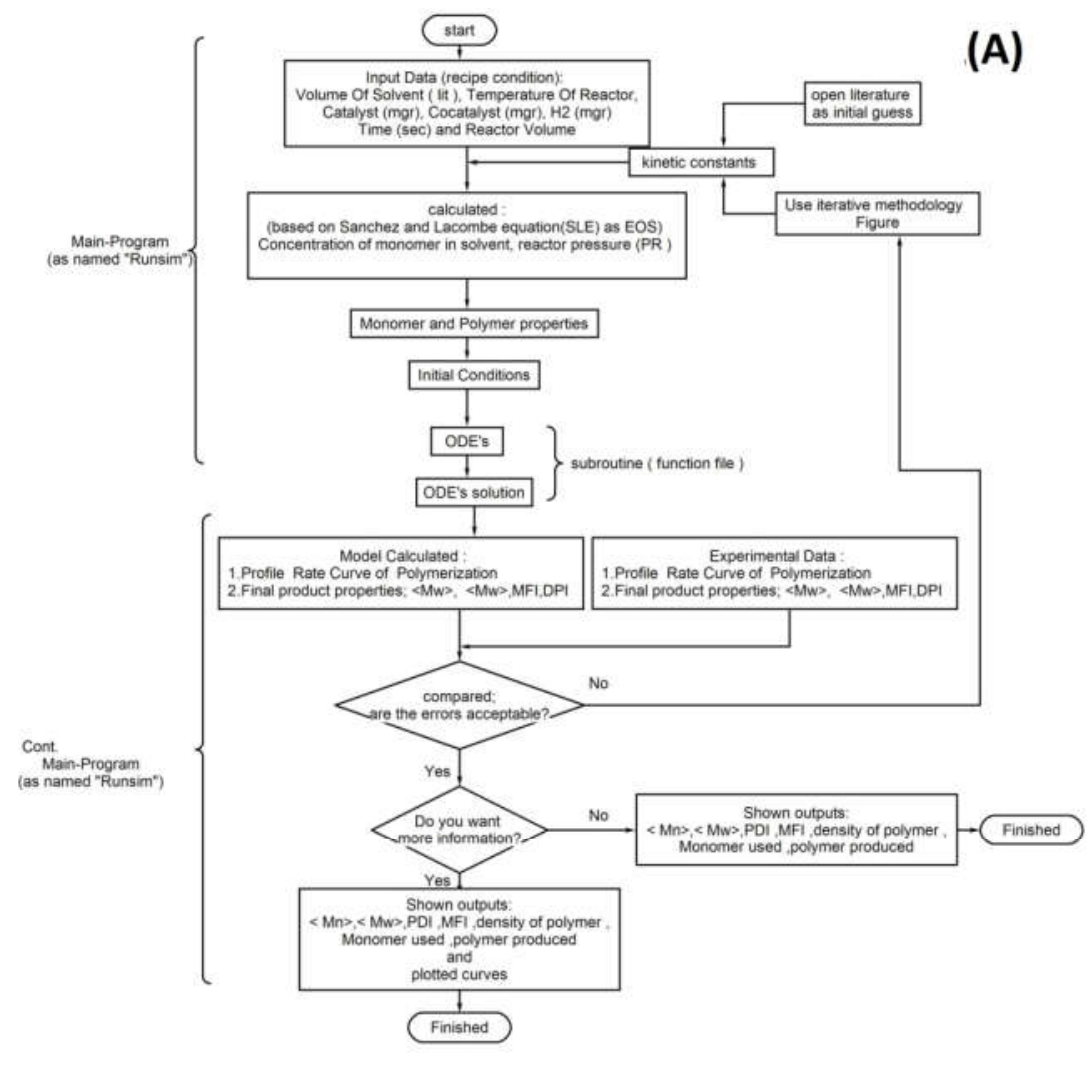

(B)

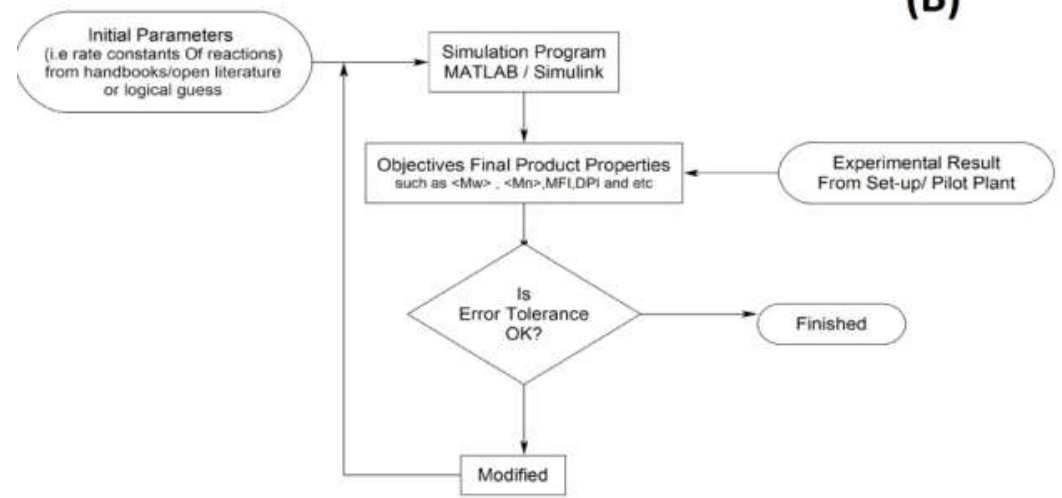

Figure 1. (A) The general algorithm modeling in this work and (B) the iterative methodology used to adjusting kinetic parameter (constants) in this work.

Bull. Chem. Soc. Ethiop. 2018, 32(2) 
Table 3. Summarized recipe for polymerization; summarized polymerization recipe; model and experimental output results.

\begin{tabular}{|c|c|c|c|c|c|c|c|c|c|c|c|c|}
\hline \multicolumn{4}{|c|}{ Recipe } & & \multicolumn{8}{|c|}{ Results (experimental/model) } \\
\hline 乙 & $\stackrel{1}{\circ}$ & 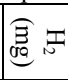 & 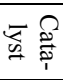 & & $\begin{array}{l}\prec \\
\text { (100 }\end{array}$ & $\frac{\pi}{0}$ & હ & 3 & 3 & $\Xi$ & 光 & $\begin{array}{l}\text { 原 } \\
\text { 总 }\end{array}$ \\
\hline \multirow[t]{2}{*}{1} & \multirow[t]{2}{*}{65} & \multirow[t]{2}{*}{0} & \multirow[t]{2}{*}{20} & Exp. $\mathrm{R}^{1}$ & 63.29 & 5.01 & 1.42 & 210259 & 863057 & 4.10 & 0.75 & \\
\hline & & & & Mod. $\mathrm{R}^{2}$ & 65.13 & 5.19 & 1.42 & 205570 & 834523 & 4.06 & 0.81 & 589.44 \\
\hline \multirow[t]{2}{*}{2} & \multirow[t]{2}{*}{70} & \multirow[t]{2}{*}{0} & \multirow[t]{2}{*}{20} & Exp. R & 72.66 & 6.5 & 1.95 & 304642 & 1104374 & 3.63 & 0.42 & \\
\hline & & & & Mod. R & 76.40 & 7.46 & 1.98 & 323780 & 1214440 & 3.75 & 0.33 & 619.37 \\
\hline \multirow[t]{2}{*}{3} & \multirow[t]{2}{*}{75} & \multirow[t]{2}{*}{0} & \multirow[t]{2}{*}{20} & Exp. R & 63.07 & 8.85 & 2.04 & 236154 & 1124367 & 4.76 & 0.4 & \\
\hline & & & & Mod. R & 67.25 & 8.92 & 2.13 & 270243 & 1178300 & 4.36 & 0.36 & 614.62 \\
\hline \multirow[t]{2}{*}{4} & \multirow[t]{2}{*}{70} & \multirow[t]{2}{*}{183} & \multirow[t]{2}{*}{10} & Exp. R & 81.33 & 11.2 & 2.27 & 29962 & 144192 & 4.81 & 37 & \\
\hline & & & & Mod. R & 88.40 & 11.4 & 2.30 & 32812.7 & 148874 & 4.54 & 36.99562 & 637.11 \\
\hline \multirow[t]{2}{*}{5} & \multirow[t]{2}{*}{70} & \multirow[t]{2}{*}{274} & \multirow[t]{2}{*}{10} & Exp. $\mathrm{R}$ & 74.61 & 11.0 & 2.05 & 24016 & 116939 & 4.87 & 62 & \\
\hline & & & & Mod. R & 76.81 & 11.2 & 2.35 & 24981.1 & 123303 & 4.94 & 61.98627 & 620.01 \\
\hline \multirow[t]{2}{*}{$6^{6}$} & \multirow[t]{2}{*}{70} & \multirow[t]{2}{*}{$2000^{5}$} & \multirow[t]{2}{*}{10} & Exp. R & & & & & & & & \\
\hline & & & & Mod. R & 64.92 & 9.34 & 2.81 & 9952.25 & 70163.4 & 7.06 & & \\
\hline \multirow[t]{2}{*}{$7^{7}$} & \multirow[t]{2}{*}{70} & \multirow[t]{2}{*}{$2500^{8}$} & \multirow[t]{2}{*}{10} & Exp. $\mathrm{R}$ & & & & & & & & \\
\hline & & & & Mod. R & 61.26 & 8.74 & 2.97 & 8353.86 & 61651.5 & 7.38 & & \\
\hline \multirow{2}{*}{\multicolumn{13}{|c|}{ X: Hydrogen molar rati }} \\
\hline & & & & & & ${ }^{5} 2000 \mathrm{~m}$ & $\mathrm{H}_{2}$ is ec & uivalent to & $0.0206 \mathrm{~mol}$ & ar ratio & & \\
\hline \multicolumn{6}{|c|}{${ }^{2}$ Model result } & $\begin{array}{l}{ }^{6} \text { Mather } \\
\text { grade. }\end{array}$ & atically & alculated. & But in fac & this $\mathrm{p}$ & roduct is & ff or wax \\
\hline $\begin{array}{l}{ }^{3} 18 \\
\text { ratio }\end{array}$ & $\operatorname{lg~} \mathrm{H}_{3}$ & is eq & ivalen & to $0.004 \mathrm{C}$ & 6 molar & ${ }^{7} 2500 \mathrm{~m}$ & $\mathrm{H}_{2}$ is eq & divalent to & $0.0243 \mathrm{mo}$ & ar ratio & & \\
\hline $\begin{array}{l}47 \\
\text { ratio }\end{array}$ & & & & 0.00 & molar & $\begin{array}{l}{ }^{8} \text { Math } \\
\text { grade. }\end{array}$ & & liculated. & But & & & \\
\hline
\end{tabular}

After validated model, the data run 6 and 7 come from the model. The results from Table 3 demonstrated that in the absence of hydrogen, the polymerization rate increased up to $70{ }^{\circ} \mathrm{C}$ and then decreased at $75{ }^{\circ} \mathrm{C}$. This claim can be verified by investigating the yield amount of products. Because of the polymerization rate has a direct impact on the yield. Meanwhile, increasing reaction temperature leads to increasing deactivation constant $\left(\mathrm{K}_{\mathrm{d}}\right)$ of the catalyst. This conclusion is one of the important constraints of the reaction.

By referring to Table 3, the other important conclusion is that increasing reaction temperature leads to decreasing yield of the catalyst. The reason for this phenomenon might be justified due to catalyst deactivation by over reduction of the catalyst sites or via alkylation process with the Lewis base [27].

In order to investigate the effect of varying the hydrogen concentration on the profile polymerization rate, Figure 3 has been plotted at $70{ }^{\circ} \mathrm{C}$ reactor temperature. Because it is concluded that $70{ }^{\circ} \mathrm{C}$ reactor temperature is the best condition with a maximum yield of catalyst (Table 3; comparing yield for run (1,2 and 3)). To verify the performance of the model, Figure 3 is compared the experiment with the model profile polymerization rate. Figure 3 indicates that each of both profile rate in the same condition has a fairly good consistent with each other in an acceptable margin of error. On the other hand, the error margin of final product properties such as $\mathrm{M}_{\mathrm{w}}$, DPI, and MFI between model output results and experimental data is acceptable as well (Table 3). Accordingly, it is concluded that the model has been validated.

It is worth mentioning that according to Arrhenius equation, the overall activation energy for the polymerization $\left(E_{a}\right)$ is dependent on temperature and independent on hydrogen concentrations [14]. The overall activation energy has been calculated by Eq. (6) and Figure 4(A). It is notable that the activation energy obtained in this work is in line with the literature data as shown in Table 4. From Figure 5(A), the constants of Eq. (5) could be estimated for predicting MFI by average $\mathrm{M}_{\mathrm{W}}$. 

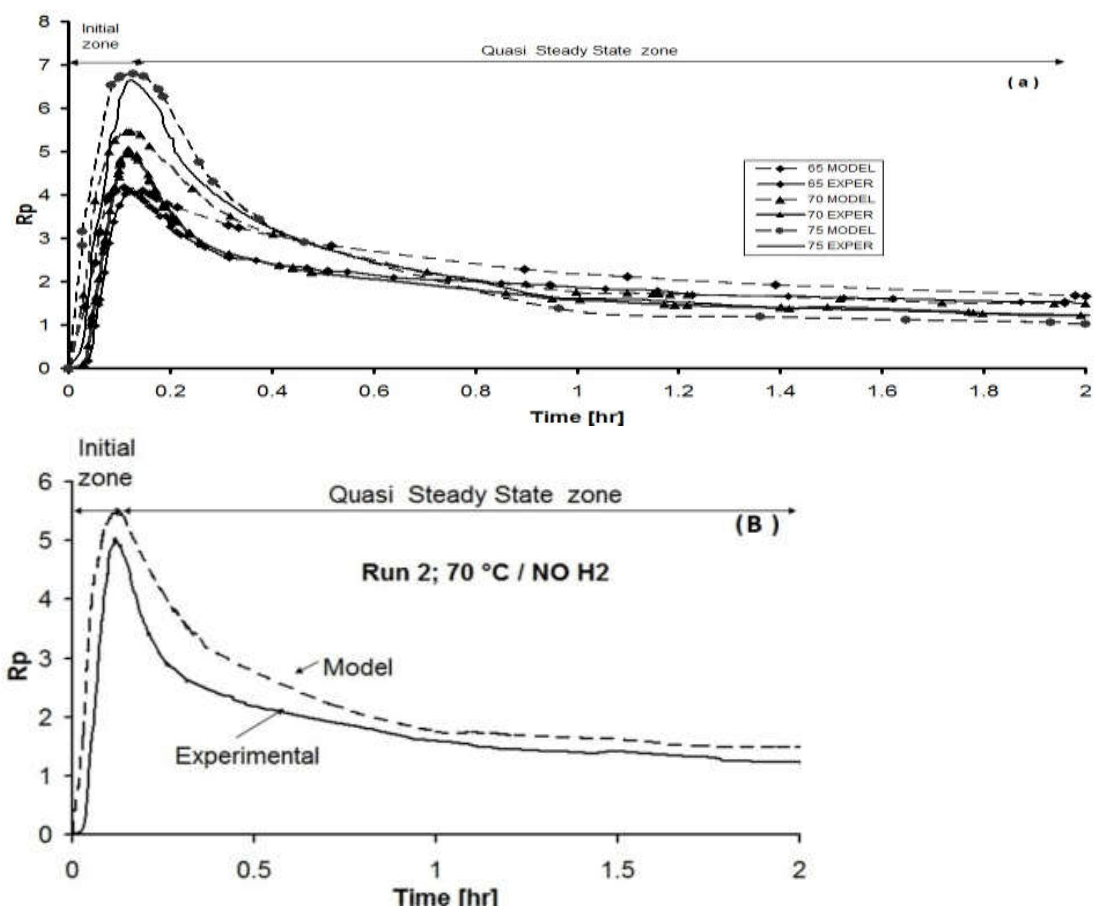

Figure 2. The comparison of experimental and model profile rate in the absence of hydrogen at a different temperature: (a) the comparison of the model and experimental altogether; run $(1,2,3)$ and $(b)$ the comparison of the model and experimental run 2.

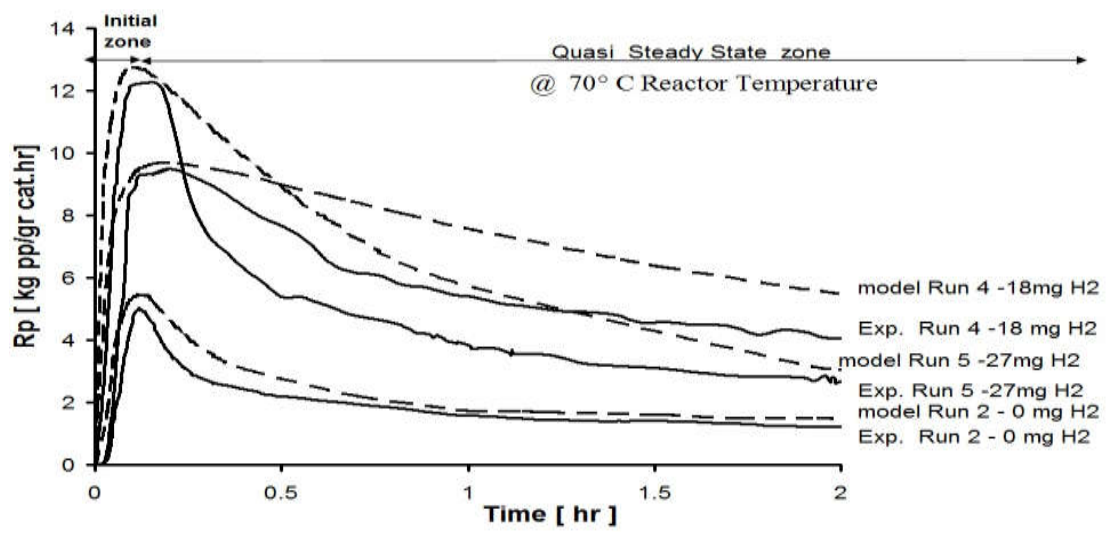

Figure 3. The comparison of experimental and model profile rate in the presence of different hydrogen concentration at the constant temperature $70^{\circ} \mathrm{C}$. 

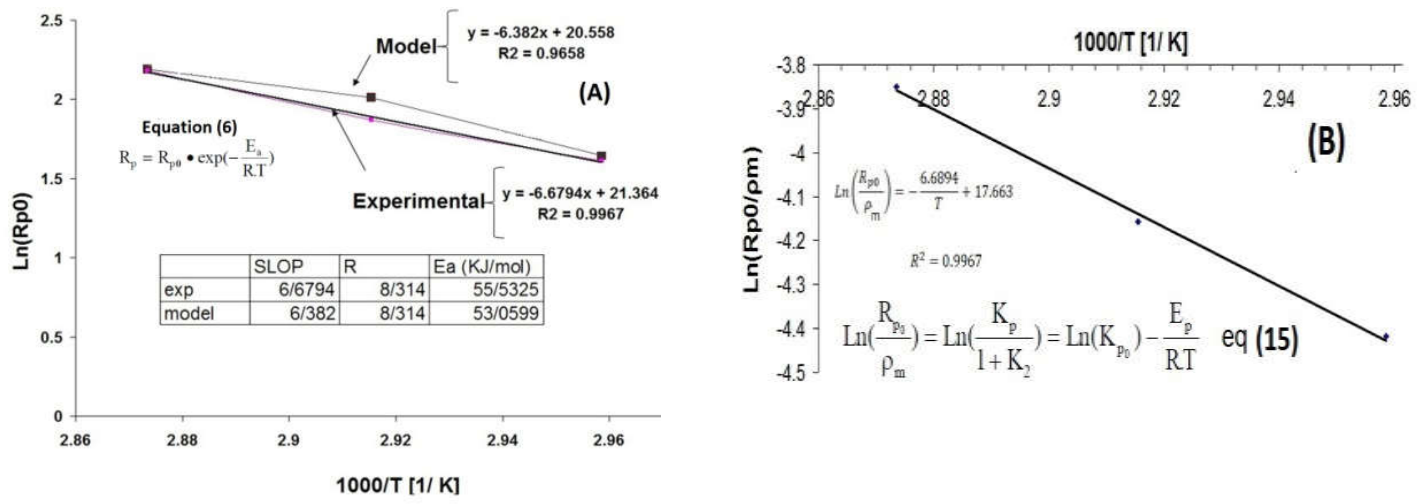

Figure 4. (A) obtaining $E_{a}$ by Arrhenius plot of the initial polymerization rates $\mathrm{Rp}_{0}$ at a different temperature; obtaining constants of Eq. (6), the relation of $\mathrm{M}_{\mathrm{w}}$ with MFI and (B) calculation of propagation constant $\mathrm{K}_{\mathrm{p}}$ and $\mathrm{E}_{\mathrm{p}}$ by using Eq. (15).

Table 4. The compaction of reported activation energies $\left(\mathrm{E}_{\mathrm{a}}\right)$ in propylene polymerization system.

\begin{tabular}{|c|l|l|l|}
\hline \multicolumn{1}{|c|}{ Catalyst system } & Phase & $\mathrm{E}_{\mathrm{a}}(\mathrm{kJ} / \mathrm{mol})$ & Reference \\
\hline$\delta$ - $\mathrm{TiCl}_{3}(1 / 3) \mathrm{AlCl}_{3} / \mathrm{DEAC}$ & Slurry & 53.9 & Yuan et. al. $[28]$ \\
\hline $\mathrm{TiCl}_{3} / \mathrm{DEAC}$ & Slurry & 57.7 & Soares et. al. $[18]$ \\
\hline $\mathrm{MgCl}_{2} / \mathrm{TiCl}_{4} / \mathrm{phthalate} /$ silane/TEA & Liquid pool & 58.6 & Al-haj Ali et al. $[14]$ \\
\hline $\mathrm{MgCl}_{2} / \mathrm{TiCl}_{4} / \mathrm{phthalate} /$ silane/TEA & Slurry & 55.53 & This study (Exp.) \\
\hline $\mathrm{MgCl}_{2} / \mathrm{TiCl}_{4} / \mathrm{phthalate/silane/TEA}$ & Slurry & 53.05 & This study (Model) \\
\hline
\end{tabular}

Equation (12) or polymerization rate has three parameters that should be determined (i.e. $\mathrm{K}_{\mathrm{p}}$, $\mathrm{k}_{1}$, and $\left.\mathrm{k}_{2}\right)$. The fit is done in two steps, in the first step the value of $\left(\mathrm{k}_{\mathrm{p}} /\left(1+\mathrm{k}_{2}\right)\right)$ is obtained by putting $X=0$ (no hydrogen), then the values of $k_{1}$ and $k_{2}$ are estimated. The first step: as the active sites of catalyst are heterogeneity, the calculated value of $K_{P}$ is an average amount. This value is determined using the experiments without hydrogen, run 1, 2 and 3 . When no hydrogen is used, $\mathrm{f}_{\mathrm{H} 2}$ can be rewritten as:

If $\mathrm{X}=0$ (no hydrogen); Eq. (12) converts to the following equation:

$R_{p_{0}}=\frac{R_{p_{0}}^{\prime}}{\rho_{m}}=\frac{K_{p}^{\prime}}{1+K_{2}}$

where $R_{p_{0}}^{\prime}[\mathrm{mol} / \mathrm{L} . \mathrm{s}]$ and $R_{p_{0}}\left[\mathrm{~kg} / \mathrm{g}_{\text {cat }} \cdot \mathrm{h}\right]$, and with rearrangement we have.

Here $\rho_{\mathrm{m}}$ is monomer density. The Arrhenius plot for $\left(\mathrm{K}_{\mathrm{P}} / 1+\mathrm{k}_{2}\right)$, Figure $4(\mathrm{~B})$, shows an excellent fit with a linear correlation coefficient $\left(\mathrm{R}^{2}\right)$ of 0.9967 . Based on these results, the dependency of $\left(\mathrm{kp} / \mathrm{l}+\mathrm{k}_{2}\right)$ on reaction temperature has the following form:

$K_{p}=K_{p_{0}} \cdot\left(1+K_{2}\right) \cdot \exp \left(-\frac{E_{p}}{R \cdot T}\right)$

Then we have:

$\operatorname{Ln}\left(\frac{R_{p_{0}}}{\rho_{m}}\right)=\operatorname{Ln}\left(\frac{K_{p}}{1+K_{2}}\right)=\operatorname{Ln}\left(K_{p_{0}}\right)-\frac{E_{p}}{R \cdot T}$ 
From the slope of the fitted line in Figure 4(B), the activation energy of propagation reaction of the polymerization $E_{p}$ is obtained. Table 5 shows the summarized results from this research (in the slurry process) and compared with the other researcher (in bulk process). The results of the model are in line with what was expected.

Since the most reactions in the polymerization belong to propagation reactions, as expected, the overall activation energy $E_{a}$ should be very close to the propagation activation energy $E_{p}$. Therefore, with calculating and comparing of $\mathrm{E}_{\mathrm{p}}$ with $\mathrm{E}_{\mathrm{a}}$ at least error, it could be a criterion of the accuracy and validity of the model.

For calculating $E_{p}$ is by means of dormant site generation theory by using Eq. (15) and plotting in Figure 4 (B). The figure shows an excellent fit with a linear correlation coefficient $\left(R^{2}\right)$ of 0.9967 . Then from the slop of the fitted line in Figure $4(B), E_{p}$ is obtained. It is interesting to note that with comparing $\mathrm{E}_{\mathrm{a}}$ and $\mathrm{E}_{\mathrm{p}}$, the difference is only $4 \%$ error (Table 5). This is another reason that the model was well enough validated. In addition, the Dormant Site Generation Theory has accurately justified the profile curve rate of propylene polymerization.

In this respect, Al-haj Ali et al. [14], using the experimental method in liquid pool media, have been calculated $E_{a}$ and $E_{p}$ with approximately $12.8 \%$ error (Table 5). Therefore, this error difference has a significant effect on the subsequent calculations such as $\mathrm{Rp}_{0}, \mathrm{~K}_{1}$, and $\mathrm{K}_{2}$ (summarized in Table 5).

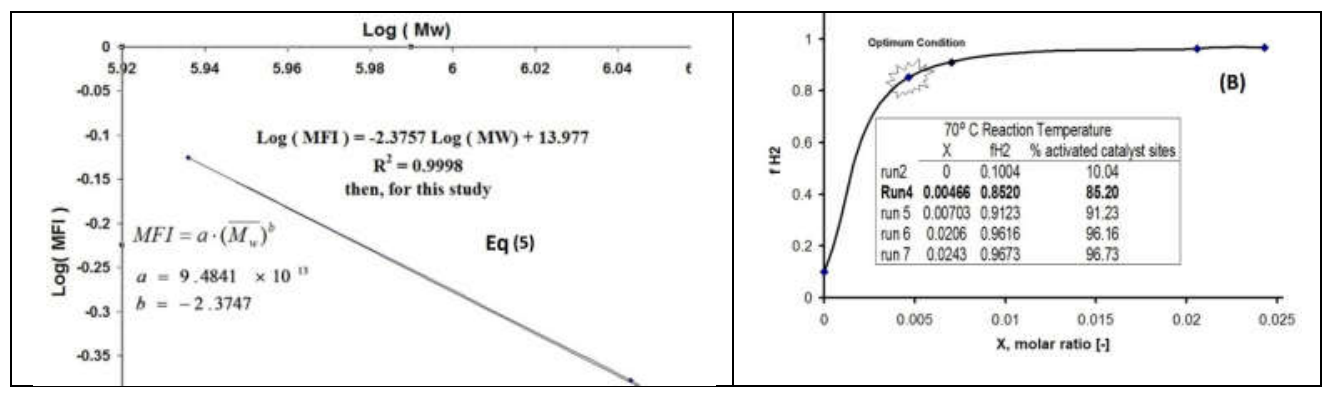

Figure 5. (a) Obtaining constants of Eq. (5), the relation of $\mathrm{M}_{\mathrm{w}}$ with MFI and (b) the relation of the fraction of active sites by hydrogen concentration in system $\mathrm{f}_{\mathrm{H} 2}$.

Table 5. The comparison of the kinetic constants obtained in this work with literature work.

\begin{tabular}{|c|l|c|c|c|c|c|}
\hline & Condition & $\begin{array}{c}\text { Overall } \mathrm{E}_{\mathrm{a}} \\
{[\mathrm{kJ} / \mathrm{mol}]}\end{array}$ & $\begin{array}{c}\mathrm{E}_{\mathrm{p}} \\
{[\mathrm{kJ} / \mathrm{mol}]}\end{array}$ & $\begin{array}{c}\text { Error } \\
\%\end{array}$ & $\begin{array}{c}K_{p_{0}} \\
{\left[\mathrm{~m}^{3} / g r_{\text {cat }} . h r\right]}\end{array}$ & $\begin{array}{c}\mathrm{K}_{2} \\
{[-]}\end{array}$ \\
\hline \multirow{3}{*}{$\begin{array}{c}\text { Al-haj Ali } \text { et al. }[14] \\
\text { slurry-bulk }\end{array}$} & Liquid pool & 58.6 & 67.22 & 12.82 & $6.41 \times 10^{8}$ & 8.02 \\
\cline { 2 - 7 } & Catalyst system: & $\mathrm{MgCl}_{2} / \mathrm{TiCl}_{4} / \mathrm{phthalate} / \mathrm{silane} / \mathrm{TEA}$ \\
\hline \multirow{2}{*}{ This work } & Slurry in heptane & 53.0599 & 55.61 & 4.5 & $4.69 \times 10^{6}$ & 8.97 \\
\cline { 2 - 6 } & Catalyst system: & $K_{1}=-1.529 \cdot T^{2}+555.24 \cdot T-4.226 \times 10^{6}$ \\
$\mathrm{MgCl}_{2} / \mathrm{TiCl}_{4} / \mathrm{phthalate} / \mathrm{silane} / \mathrm{TEA}$
\end{tabular}

By using the dormant theory, Eq. (12) is obtained. On the other hand, $\mathrm{K}_{1}$ and $\mathrm{K}_{2}$ can be estimated using the output of the model and Figure 4(a). The equation predicts the fraction of the catalyst active sites via hydrogen molar ratio (X). For instance, if there is no hydrogen in the 
polymerization system $(\mathrm{X}=0)$, only $10 \%$ of the potential of the catalytic is active, and about $90 \%$ of it is laid down and unused (Figure 5(B)). The impact of this issue on $\mathrm{Y}$ and $\mathrm{Rp}_{0}$ is exactly clear and the model is able to predict that (Table 3 ). Then, by increasing very slightly hydrogen content such as $\mathrm{X}=0.00466$, speedily increasing fraction activated sites of the catalyst $(85.5 \%)$ (Figure 5(B)). But the increasing hydrogen content caused to be increasing deactivation catalyst $\mathrm{K}_{\mathrm{d}}$ (Table 3 ). It is not very desirable due to quickly deactivation of the catalyst. On the other side, the increased hydrogen content has an inverse effect on the $\mathrm{Rp}_{0}$ and $\mathrm{Y}$, in the other words; it may lead to changing final product properties and even producing off-grade or wax product.

\section{CONCLUSION}

In this paper, it has been presented a validated mathematical model based on moment approach for an isothermal slurry polymerization of propylene with Ziegler-Natta catalysts. that cable to calculate the most important indices of final product properties, such as melt flow index (MFI), number average molecular weight $\left(\mathrm{M}_{n}\right)$, weight average molecular weight $\left(\mathrm{M}_{\mathrm{w}}\right)$ and poly dispersity index (PDI), and hydrogen response of propylene polymerization system. The model output was in good agreement with experimental results and revealed. At the $70{ }^{\circ} \mathrm{C}$ temperature, the PDI was a minimum amount, indicating optimum polydispersity of polymer chains. In absence of hydrogen, increase in temperature led to a reduction of molecular weight and enhancement of MFI. The activation energy did not depend on the presence and absence of hydrogen as well as hydrogen concentration. The model could be able to predict deactivation constant of unknown catalyst in the presence or absence of hydrogen in the polymerization system.

\section{REFERENCES}

1. Shaffer, W.K.A.; Ray, W.H. Polymerization of olefins through heterogeneous catalysis. XVIII. A kinetic explanation for unusual effects. Appl. Polym. Sci. 1997, 65, 1037-1052.

2. Busico, V.; Cipullo, R.; Mingione, A.; Rongo, L. Accelerating the research approach to Ziegler-Natta catalysts. Ind. Eng. Chem. Res. 2016, 55, 2686-2695.

3. Reginato, A.S.; Zacca, J.J.; Secchi A.R.; Modeling and simulation of propylene polymerization in nonideal loop reactors. AIChE J. 2003, 49, 2642-2654.

4. Neto, A.G.M.; and Pinto, J.C.; Steady-state modeling of slurry and bulk propylene polymerizations. Chem. Eng. Sci. 2001, 56, 4043-4057.

5. Mckenna T.F.; Dupuy, J.; Spitz, R. Modeling of transfer phenomena on heterogeneous Ziegler catalysts: Differences between theory and experiment in olefin polymerization (an introduction). Appl. Polym. Sci. 1995, 57, 371-384.

6. Sarkar, P.; Gupta, S.K. Steady-state simulation of continuous-flow stirred-tank slurry propylene polymerization reactors. Polym. Eng. Sci. 1992, 32, 732-742.

7. Sarkar, P.; Gupta, S.K. Dynamic simulation of propylene polymerization in a continuous flow stirred tank reactors. Polym. Eng. Sci. 1993, 33, 368-374.

8. Sarkar, P.; Gupta, S.K. Modelling of propylene polymerization in an isothermal slurry reactor. Polymer 1991, 32, 2842-2852.

9. Luo, Zh.H.; Zheng, Y.; Cao, Z.K.; Wen, S.H. Mathematical modeling of the molecular weight distribution of polypropylene produced in a loop reactor. Polym. Eng. Sci. 2007, 47, 1643-1649.

10. Chatzidoukas, C.; Perkins, J.D.; Pistikopoulos, E.N.; Kiparissides, C. Optimal grade transition and selection of closed-loop controllers in a gas-phase olefin polymerization fluidized bed reactor. Chem. Eng. Sci. 2003, 58, 3643-3658.

11. Samson, J.J.C.; Bosman, J.B.; Weickert, G.; Westerterp, K.R. Liquid-phase polymerization of propylene with a highly active Ziegler-Natta catalyst. Influence of hydrogen, cocatalyst, and electron donor on reaction kinetics. J. Polym. Sci. Part A: Polym. Chem. 1999, 37, $219-$ 232. 
12. Pater, J.T.M.; Weickert, G.; van Swaaij, W.P.M. Polymerization of liquid propylene with a fourth generation Ziegler-Natta catalyst: Influence of temperature, hydrogen, monomer concentration, and prepolymerization method on polymerization kinetics. J. Appl. Polym. Sci. 2003, 87, 1421-1435.

13. Shimizu, F.; Pater, J.T.M.; Van Swaaij, W.P.M.; Weickert, G. Kinetic study of a highly active $\mathrm{MgCl}_{2}$-supported Ziegler-Natta catalyst in liquid pool propylene polymerization. II. The influence of alkyl aluminum and alkoxysilane on catalyst activation and deactivation. $J$. Appl. Polym. Sci. 2002, 83, 2669-2679.

14. Al-haj, A.M.; Betlem, B.; Roffel, B.; Weickert, G. Hydrogen response in liquid propylene polymerization: Towards a generalized model. AIChE J. 2006, 52, 1866-1876.

15. Guastalla, G.; Gianinni, U. The influence of hydrogen on the polymerization of propylene and ethylene with a $\mathrm{MgCl}_{2}$ supported catalyst. Makromol. Chem., Rapid Commun. 1983, 4 , 519-527.

16. Spitz, R.; Masson, P.; Bobichon, C.; Guyot, A. Activation of propene polymerization by hydrogen for improved $\mathrm{MgCl}_{2}$-supported Ziegler-Natta catalysts. Makromol. Chem. 1989, 190, 717-723.

17. Rishina, L.A.; Vizen, E.I.; Sosnovskaja, L.N.; Dyachkovsky, F.S. Study of the effect of hydrogen in propylene polymerization with $\mathrm{MgCl}_{2}$ supported Ziegler-Natta catalyst-Part 1 . Kinetics of polymerization. Eur. Polym. J. 1994, 30, 1309-1313.

18. Soares, J.B.P.; Hamielec, A. Kinetics of propylene polymerization with a non-supported heterogeneous Ziegler-Natta catalyst-effect of hydrogen on rate of polymerization, stereoregularity, and molecular weight distribution, Polymer 1996, 37, 4607-4614.

19. Soga, K.; Siano, T. Effect of hydrogen on the molecular weight of polypropylene with Ziegler-Natta catalysts. Polym. Bull. 1982, 8, 261-268.

20. Kahrman, R.; Erdogan, M.; Bilgic T. Polymerization of propylene using a prepolymerized high-active Ziegler-Natta catalyst. I. Kinetic Studies. J. Appl. Polym. Sci. 1996, 60, 333-342.

21. Yang, X.F.; Zheng, T.; Che, L.M.; Luo, Zh.H. A dynamically distributed reactor model for identifying the flow fields in industrial loop propylene polymerization reactors. J. Appl. Polym. Sci. 2013, 128, 4302-4313.

22. Zhu, Y.P.; Luo, Z.H.; Xiao, J. Multi-scale product property model of polypropylene produced in an FBR: From chemical process engineering to product engineering. Comput. Chem. Eng. 2014, 71, 39-51.

23. Kim, S.H.; Baek, S.W.; Lee, J.C.; Lee, W.J.; Hong, S.U.; Oh, M. Dynamic simulation of liquid polymerization reactors in Sheripol process for polypropylene.J. Ind. Eng. Chem. 2016, 33, 298-306.

24. Costa G.M.N.; Kislansky, S.; Oliveira, L.C.; Pessoa, F.L.P.; Vieira de Melo, S.A.B.; Embiruc, M.; Modeling of solid-liquid equilibrium for polyethylene and polypropylene solutions with equations of state. J. Appl. Polym. Sci. 2010, 121, 1832-1849.

25. Busico, V.; Cipullo, R.; Corradini, P. Ziegler-Natta oligomerization of 1-alkenes: A catalyst's "fingerprint". Macromol. Chem. Phys. 1993, 194, 1079-1093.

26. Chadwick, J.C.; Miedema, A.; Sudmeijer, O. Hydrogen activation in propene polymerization with $\mathrm{MgCl}_{2}$-supported Ziegler-Natta catalysts: The effect of the external donor. Macromol. Chem. Phys. 1994, 195, 167-172.

27. Keii, T.; Suzuki, E.; Tamura, M.; Murata, M. Propene polymerization with a magnesium chloride supported Ziegler catalyst, 1. Principal kinetics. Macromol. Chem. Phys. 1982, 183, 2285-2304.

28. Yuan, H.G.; Taylor, T.W.; Choi, K.Y.; Ray, W.H. Polymerization of olefins through heterogeneous catalysis. 1. Low-pressure propylene polymerization in slurry with ZieglerHatta catalyst. J. Appl. Polym. Sci. 1982, 27, 1691-1706. 